\title{
Publisher Correction: Second-order spectral lineshapes from charged interfaces
}

\author{
Paul E. Ohno (1) ${ }^{1}$, Hong-fei Wang ${ }^{2}$ \& Franz M. Geiger ${ }^{1}$
}

Nature Communications https://doi.org/10.1038/s41467-017-01088-0, Article published online 18 October 2017

The original version of this Article contained an error in Equation 3b. A '+' sign incorrectly appeared instead of a '-' sign in the denominator of the right-hand side of the equation and incorrectly read:

$$
\left(\chi_{1}^{(3)}+i \chi_{2}^{(3)}\right)=\left(\frac{\kappa^{2}}{\kappa^{2}+\left(\Delta k_{z}\right)^{2}} \chi^{(3)}+i \frac{\kappa \Delta k_{z}}{\kappa^{2}+\left(\Delta k_{z}\right)^{2}} \chi^{(3)}\right)=\frac{\kappa}{\kappa+i \Delta k_{z}} \chi^{(3)}
$$

The correct form of the equation is as follows:

$$
\left(\chi_{1}^{(3)}+i \chi_{2}^{(3)}\right)=\left(\frac{\kappa^{2}}{\kappa^{2}+\left(\Delta k_{z}\right)^{2}} \chi^{(3)}+i \frac{\kappa \Delta k_{z}}{\kappa^{2}+\left(\Delta k_{z}\right)^{2}} \chi^{(3)}\right)=\frac{\kappa}{\kappa-i \Delta k_{z}} \chi^{(3)}
$$

This has now been corrected in both the PDF and HTML versions of the Article.

Published online: 15 January 2018

Open Access This article is licensed under a Creative Commons Attribution 4.0 International License, which permits use, sharing, adaptation, distribution and reproduction in any medium or format, as long as you give appropriate credit to the original author(s) and the source, provide a link to the Creative Commons license,
and indicate if changes were made. The images or other third party material in this article are included in the article's Creative Commonslicense, unless indicated otherwise in a credit line to the material. If material is not included in the article'sCreative Commons license and your intended use is not permitted by statutory regulation or exceeds the permitted use, you will need to obtain permission directly from the copyright holder. To view a copy of this license, visit http://creativecommons.org/licenses/by/4.0/.

(C) The Author(s) 2018

\footnotetext{
${ }^{1}$ Department of Chemistry, Northwestern University, Evanston, IL 60208, USA. ${ }^{2}$ Department of Chemistry and Shanghai Key Laboratory of Molecular Catalysis and Innovative Materials, Fudan University, Shanghai 200433, China. Correspondence and requests for materials should be addressed to H.-f.W. (email: wanghongfei@fudan.edu.cn) or to F.M.G. (email: geigerf@chem.northwestern.edu)
} 